\title{
Awareness and attitudes towards common mental health problems of community members in Udupi Taluk, Karnataka: A mixed method study
} \author{
Sneha Maheshwari ${ }^{\mathrm{d}}$ \\ ${ }^{a}$ Department of Health Policy, Prasanna School of Public Health, Manipal University, Karnataka, India \\ ${ }^{\mathrm{b}}$ Indian Institute of Health Management Research, Jaipur, India \\ c State Consultant, Ayushman Bharat PMJAY, Uttar Pradesh, India \\ ${ }^{\mathrm{d}}$ Dental Practitioner, Jodhpur, Rajasthan, India
}

Monica Sindhu ${ }^{\mathrm{a}}$, Sameer Phadnis ${ }^{\mathrm{b}}$, Zakariya Chouhan ${ }^{\mathrm{c}, *}$, Pallavi Saraswat ${ }^{\mathrm{a}}$,

\section{A R T I C L E I N F O}

\section{Keywords:}

Mental health

Mental illness

Awareness

Knowledge

Attitude

Stigma

\begin{abstract}
A B S T R A C T
Introduction: The aim of the present study was i) to quantify the awareness about common mental health problem, ii) to assess attitude of community members and healthcare providers towards mental health patients and identify the factors contributing to their stigma and iii) to assess perception of health care providers about National Mental Health Program in Udupi Taluk, Karnataka.

Material and methods: A mixed method observational study was done, in 212 community members of above 18 years of age through two-stage cluster sampling. Participants were presented with 2 vignettes defining individuals suffering from symptoms of mental disorders (psychosis and depression) and in-depth interviews were conducted from healthcare providers $(n=11)$. Descriptive statistics were calculated by bivariate statistical analysis to describe the responses to the variables from the questionnaire.

Result: The most commonly recognized causes of the mental health problems were unemployment, separated or divorced, among other socioeconomic factors. Psychiatrist and physician were believed to be the most helpful for providing treatment of mental health problems. The discrimination of people with a mental illness diagnosis of psychosis $(74.8 \%)$ was more as compared to depression $(25.2 \%)$. The stigmatizing attitude was found to be more in males $(22.3 \%)$ of social distancing as compared to females $(8.47 \%)$.

Conclusion: More than $60 \%$ of the community members have knowledge and awareness about causal factors of mental health problems in this region. However, there is a need to raise awareness in the community about the National Mental Health program, and services provided by the government for mental health problems.
\end{abstract}

\section{Introduction}

In India, about 50 million people live with mental illness, which estimates to $5 \%$ of the population living with mental health problems. ${ }^{1}$ According to the National Government's estimates, 1 out of 5 people in India need either psychological or psychiatric counseling. ${ }^{2}$ Due to general lack of awareness, stigma and discrimination, people with known mental health problems neglect preventive care and never seek help from health professionals. ${ }^{1,3}$ Mental wellbeing is an essential part of overall health and mental disorders account for significant morbidity and infirmity, thereby causing distress to the quality of lives significantly. Moreover, individuals with mental disorders and their families face unconcealed stigma and discrimination, which results in elimination of their basic human rights.

A lot of stakeholders such as governmental and non-governmental organizations, leaders like teachers, Sarpanchs of villages, Anganwadi workers, etc., can play a major role in raising awareness in communities and help reducing the stigma based-discrimination associated with mental illness. About $90 \%$ of individuals with mental illnesses in low and middle-income countries do not achieve even essential mental health services. ${ }^{4,5}$ This negligence remains despite irresistible indication that facilities like: essential medicines, mental therapies or treatment at early stage and community based therapy are possible, affordable and economical for various common mental health problems, and might be brought positively in primary health care (PHC) centers. ${ }^{4,6-8}$

In India, the National Mental Health Program also encourages the

\footnotetext{
* Corresponding author.

E-mail address: zak.chouhan@gmail.com (Z. Chouhan).
} 
combination of mental health into PHC: still, there has been inadequate attainment in realizing this program in practice amongst 24 of 600 districts presently covered by this program. ${ }^{6,9,10}$ Due to the association in mental and physical health, individuals with mental health problems normally are accessible to nearby PHC centers, especially individuals or patients living in rural areas, and hard to reach areas. However, PHC personnel lack the services needed to create a suitable recognition and delivery of an equitable regular attention. ${ }^{6}$ Successful training programs are essential to advance the mental health services of overall PHC and CHC personnel.

Mental illness remains unseen in India due to lack of awareness, stigma and discrimination. While there is a high level of interest to know more about mental health problems, help seeking behaviour of community members, attitude of general population towards mentally ill patients. The measure of social distancing is intended to provide an insight into individual practices and beliefs, as opposed to perception of community actions.

The current study was conducted with the aim to assess the awareness and attitude of community members towards the patients suffering from mental health problems (depression and psychosis in particular) and identifies the factors contributing to their stigma and, also perceptions of the health care providers related to mental health problems in community and, about National Mental Health Program in Udupi Taluk, Karnataka.

\section{Material and methods}

The present mixed method observational study was carried out between January and June 2017 in urban area (wards) and rural area (villages) of Udupi Taluk. The location Udupi Taluk was chosen for convenience. also, since it is an area with relatively higher literacy and health indicators, it was hypothesized that the awareness will be higher and discrimination would be lower. The study population included community members above 18 years of age and 11 in-depth interviews were conducted from health care providers from $\mathrm{PHC}, \mathrm{CHC}$, and district hospital. The sample size was calculated as 212 , at $95 \%$ CI taking $10 \%$ absolute precision, and design effect 2 . The sample size also accounts for a hypothesized frequency of awareness of $50 \%$. For qualitative effect, 11 interviews were conducted from health care providers that included one psychiatrists, one psychologists, two medical officers, four nurses and three community health workers from public healthcare centers of Udupi Taluka.

Two stage cluster-sampling technique was used to sample the community members, at 1st stage; the villages from rural areas and wards from urban areas were selected and at 2nd stage using PPS (probability proportional to size), selection of households from wards and villages done and then based on gender the participants were selected.

An interviewer administered, standard questionnaire was used in the study. The questionnaire and vignettes used were compiled from validated source questionnaire from one of the study and to collect data using interview method. The questionnaire and vignettes used were adapted from Michelle Kermode (a mental health training program for community health workers in India) ${ }^{11}$ (Table 1 ). In depth interview

Table 1

Table showing mean of total Knowledge (\%) about causative factors of Mental Illness.

\begin{tabular}{lll}
\hline Possible causes of mental illness & Yes & No \\
\hline Infection & $54.61 \%$ & $76.98 \%$ \\
Arguments & $75.62 \%$ & $42.61 \%$ \\
Life decision & $78.65 \%$ & $44.37 \%$ \\
Addiction & $79.36 \%$ & $50.28 \%$ \\
Work difficulties & $79.40 \%$ & $53.24 \%$ \\
Financial problems & $78.12 \%$ & $46.62 \%$ \\
Death of close one & $79.73 \%$ & $54.09 \%$ \\
Genetic & $67.15 \%$ & $74.51 \%$ \\
\hline
\end{tabular}

were conducted with the healthcare providers. Each interview was audio recorded. The ethical clearance for the study was obtained from the Institutional Ethics Committee, Kasturba Medical College, Manipal and registered with CTRI (REF/2017/01/013095).

\subsection{Statistical analysis}

Data entry and analysis was done using statistical software (SPSS 16.0, Chicago, USA). Descriptive statistics were calculated by bivariate statistical analysis. The total knowledge score (range $0-8$ ) about causative factors of mental illness was calculated separately for independent variables. The overall knowledge was reported in percentage (0-100\%). The cut-off p-value for statistical significance was 0.05 . The data was tested for normality, and the variables tested for overall knowledge about causative factors of mental illness. The results of this test rejected the hypothesis of normality (as p $<0.05$ for knowledge). The Kruskal Wallis was the test used for variables with more than two independent groups (included education, age and marital status) and Mann Whitney $U$ test was used for variables having two independent groups (included gender and demographic regions). Pearson's coefficient was used to analyze the correlation between total knowledge (range $0-100 \%$ ) of community members about causative factors of mental illness with overall score of social distancing.

\section{Results}

There were 212 participants from the community who were interviewed for the study. The mean age of participants was 30 years, with a range of $18-50$ years of age. More than $60 \%$ of the participants were married (65.9\%). Approximately, one third of the participants (32.7\%) had completed college/university. Majority of the participants (71.0\%) were from rural areas. The respondents were read the two vignettes first and after that they were asked to name the problem (more than one answer was possible). Only "depression" and "psychosis" were considered correct answers to the suitable vignettes. Males had the vignette where character had psychosis. Out of all the males interviewed, $87.38 \%$ correctly recognized the problem. Females had the vignette where character had depression. Out of all the females interviewed, 54.05\% correctly recognized the problem.

As compared to females, males were able to recognize mental illness more correctly. Majority of respondents (36.9\%) considered that seeing a psychiatrist would be most helpful. An equal number (23.5\%) of respondents believed that talking to family/friends and visiting to doctor would be helpful.

Level of help for the following (that is, what is the role of each of the following): Above $60 \%$ participants stated that psychiatrist (87.4\%), close family member (69.6\%), local doctors (60.3\%), ayurvedic doctors (47.7\%) are helpful. Additionally, majority of people did not believe in seeking help from neither a witch doctor (72.9\%), nor a priest (69.6\%).

The respondents were asked structured questions for the knowledge about causative factors of mental illness. From knowledge score (total number of correct answers out of 8) the mean is 5.5 and total knowledge (\%) about causative factors of mental illness mean is 69.3. However, there was no major difference found between knowledge in rural and urban, age, gender, education and marital status. The responses to the open-ended questions about the likely cause of the problems described in the psychosis and depression vignette were relatively similar (Table 2). Through extreme the most common reason for the problems in these cases were the statements that the individuals described in the vignettes were not married, whereas, less commonly reported causes were included infection. The inherited or genetic causes of mental illness was found to have mixed reviews from participants i.e., $67.15 \%$ believed that genetic or inherited may be the cause of mental illness and on other side, $74.51 \%$ participants did not agree with this statement.

Perceived risk groups for mental disorders described in the 
Table 2

Table showing total knowledge of community members about causative factor of mental illness.

\begin{tabular}{lll}
\hline & $\begin{array}{l}\text { Total Knowledge (\%) about causative } \\
\text { factors of Mental Illness (Mean) }\end{array}$ & $\begin{array}{l}\text { p- value (at } \\
95 \% \mathrm{CI})\end{array}$ \\
\hline $\begin{array}{l}\text { Demographic } \\
\text { Rural }\end{array}$ & $68.91 \%$ & .643 \\
Urban & $70.56 \%$ & \\
Age & & .105 \\
Young Age & $64.94 \%$ & \\
Middle Age & $72.13 \%$ & $\mathbf{0 . 0 0 2}$ \\
Old Age & $72.22 \%$ & \\
Gender & & .063 \\
Male & $63.83 \%$ & \\
Female & $74.55 \%$ & \\
Marital status & & \\
Single & $63.10 \%$ & \\
Married & $72.61 \%$ & .634 \\
Widowed & $50.00 \%$ & \\
Divorced & $79.17 \%$ & \\
Separated & $81.25 \%$ & \\
Education & & \\
Never attended & $73.61 \%$ & \\
$\quad$ school & & \\
Completed b/w $1 \& 4$ & $72.32 \%$ & \\
$\quad$ years & & \\
Completed b/w & $69.34 \%$ & \\
$\quad$ 5\&11 years & & \\
Completed class 12 & $66.28 \%$ & \\
Completed college/ & $69.64 \%$ & \\
$\quad$ university & & \\
\hline
\end{tabular}

depression and psychosis vignettes: The younger and older individuals were mostly estimated as less likely or no difference than others to develop the mental disorders. The exceptions were that women were more likely than men at increased risk of depression but no difference in gender was accounted.

The total knowledge of the participants about the causative factors of mental illness is shown in Table 3 . The knowledge about causative factors was significantly higher in females (74.55\%) than the knowledge of males (63.83\%) ( $\mathrm{p}>0.05)$.

The attitude of community members towards patients suffering from mental health problems and identifying the factors contributing to their (social distancing) proxy stigma was asked. Majority of the respondents interviewed said that the persons in both depression (95.5\%) and psychosis (92.4\%) vignettes would get better if appropriate treatment or help is received. Also, the majority of respondents agreed that the person could discriminate in situation of psychosis.

Table 3

Correlations between knowledge and social distancing (proxy stigma).

\begin{tabular}{|c|c|c|c|}
\hline & & $\begin{array}{l}\text { Overall social } \\
\text { distancing or } \\
\text { stigmatizing } \\
\text { behaviour practiced } \\
\text { by community, } \\
\text { towards mentally ill } \\
\text { patients (in \%) }\end{array}$ & $\begin{array}{l}\text { Total Knowledge } \\
\text { (\%) about } \\
\text { causative factors } \\
\text { of Mental Illness }\end{array}$ \\
\hline \multirow{2}{*}{$\begin{array}{l}\text { Overall social } \\
\text { distancing and } \\
\text { stigmatizing } \\
\text { behaviour } \\
\text { practices by } \\
\text { community, } \\
\text { towards mentally } \\
\text { ill patients (in \%) }\end{array}$} & $\begin{array}{l}\text { Pearson } \\
\text { Correlation } \\
\text { Sig. (2- } \\
\text { tailed) }\end{array}$ & $\begin{array}{l}1 \\
.001\end{array}$ & $-.381 * *$ \\
\hline & $\mathrm{N}$ & 212 & 212 \\
\hline \multirow[t]{2}{*}{$\begin{array}{l}\text { Total Knowledge (\%) } \\
\text { about causative } \\
\text { factors of Mental } \\
\text { Illness }\end{array}$} & $\begin{array}{l}\text { Pearson } \\
\text { Correlation } \\
\text { Sig. (2- } \\
\text { tailed) }\end{array}$ & $\begin{array}{l}-.381 * * \\
.001\end{array}$ & 1 \\
\hline & $\mathrm{N}$ & 212 & 212 \\
\hline
\end{tabular}

$* *$. Correlation is significant at the 0.05 level (2-tailed).
The respondents were asked whether they agreed with a range of attitudinal statements relating to the social distancing (proxy stigma) persons described in the vignettes. For both the depression and the psychosis vignettes at reference, a majority of participants agreed that the person could socialize, tell someone about the problem and was willing to work (after treatment or correct type of help). Additionally, a significant minority perceived the person described in the vignettes as dangerous.

The association between total knowledge about causative factors of mental illness with social distancing (proxy stigma) behaviour practiced by community members towards mentally ill patients was found to be statistically associated ( $\mathrm{p}=0.001$ at $95 \% \mathrm{CI}$ and $\mathrm{r}=-0.381)$. This indicates that there was a moderate reduction of stigma with increase in knowledge about causative factors of mental illness (Table 4).

For both the vignettes, a majority perceived that the persons described in the vignettes should tell their problems to family members, friends or close ones. The social distancing association with gender was found to be significantly associated $(\mathrm{p}=0.001)$. The stigmatizing behaviour was found to be more in males as compared to females. There was no association found in other socio-demographic factors with social distancing (Table 5).

\section{Discussion}

The findings suggest that discrimination of people with a mental illness diagnosis of psychosis $(74.8 \%)$ was more as compared to depression $(25.2 \%)$. The stigmatizing attitude was found to be more in males $(22.3 \%)$ of social distancing as compared to females $(8.47 \%)$. There was no association found in other socio-demographic factors with social distancing. Whereas, the study done by Venkatesh et al. found that prevalence of stigma towards mentally ill patients was $74.6 \%$ and high prevalence of stigma was observed among females and community members with higher income. ${ }^{12}$

The total knowledge about causative factors of mental illness was found to be associated with gender $(\mathrm{p}<0.05)$. The knowledge about causative factors was significantly higher in females $(74.55 \%)$ than the

Table 4

Association between social distancing (proxy Stigma) practiced with sociodemographic factors.

\begin{tabular}{|c|c|c|c|c|}
\hline \multicolumn{2}{|c|}{ Socio-Demographic Factor } & \multirow{2}{*}{$\begin{array}{l}\text { Mean social distancing } \\
\text { (proxy stigma) score } \\
\text { (in \%) } \\
15.53\end{array}$} & \multirow{2}{*}{$\begin{array}{l}\text { Mean } \\
\text { Rank } \\
107.93\end{array}$} & \multirow{2}{*}{$\begin{array}{l}\text { p- } \\
\text { Value } \\
0.859\end{array}$} \\
\hline Demographic & Rural & & & \\
\hline & Urban & 14.19 & 106.44 & \\
\hline \multirow[t]{3}{*}{ Age } & $\begin{array}{l}\text { Young Age } \\
(18-30)\end{array}$ & 15.85 & 127.77 & 0.941 \\
\hline & $\begin{array}{l}\text { Middle Age } \\
(31-50)\end{array}$ & 13.33 & 88.69 & \\
\hline & $\begin{array}{l}\text { Old Age (51 and } \\
\text { above) }\end{array}$ & 17.33 & 107.03 & \\
\hline \multirow[t]{2}{*}{ Gender } & Male & 22.33 & 127.77 & 0.001 \\
\hline & Female & 8.47 & 88.69 & \\
\hline \multirow{5}{*}{$\begin{array}{r}\text { Marital } \\
\text { status }\end{array}$} & Single & 16.45 & 112.13 & 0.331 \\
\hline & Married & 14.33 & 105.33 & \\
\hline & Widowed & 30.00 & 136.92 & \\
\hline & Divorced & 0.00 & 58.50 & \\
\hline & Separated & 10.00 & 102.25 & \\
\hline \multirow[t]{5}{*}{ Education } & $\begin{array}{l}\text { Never attended } \\
\text { school }\end{array}$ & 15.56 & 108.22 & 0.412 \\
\hline & $\begin{array}{l}\text { Completed b/w } \\
1 \& 4 \text { years }\end{array}$ & 12.86 & 104.34 & \\
\hline & $\begin{array}{l}\text { Completed b/w } \\
5 \& 11 \text { years }\end{array}$ & 17.19 & 110.27 & \\
\hline & $\begin{array}{l}\text { Completed class } \\
12\end{array}$ & 20.00 & 119.56 & \\
\hline & $\begin{array}{l}\text { Completed } \\
\text { college/ } \\
\text { university }\end{array}$ & 11.14 & 98.74 & \\
\hline
\end{tabular}


Table 5

Association between social distancing (proxy Stigma) practiced with sociodemographic factors.

\begin{tabular}{|c|c|c|c|c|}
\hline \multicolumn{2}{|c|}{ Socio-Demographic Factor } & \multirow{2}{*}{$\begin{array}{l}\text { Mean social distancing } \\
\text { (proxy stigma) score } \\
\text { (in \%) } \\
15.53\end{array}$} & \multirow{2}{*}{$\begin{array}{l}\text { Mean } \\
\text { Rank } \\
107.93\end{array}$} & \multirow{2}{*}{$\begin{array}{l}\text { p- } \\
\text { value } \\
0.859\end{array}$} \\
\hline Demographic & Rural & & & \\
\hline & Urban & 14.19 & 106.44 & \\
\hline \multirow[t]{3}{*}{ Age } & $\begin{array}{l}\text { Young Age } \\
(18-30)\end{array}$ & 15.85 & 127.77 & 0.941 \\
\hline & $\begin{array}{l}\text { Middle Age } \\
(31-50)\end{array}$ & 13.33 & 88.69 & \\
\hline & $\begin{array}{l}\text { Old Age (51 and } \\
\text { above) }\end{array}$ & 17.33 & 107.03 & \\
\hline \multirow[t]{2}{*}{ Gender } & Male & 22.33 & 127.77 & 0.001 \\
\hline & Female & 8.47 & 88.69 & \\
\hline \multirow{5}{*}{$\begin{array}{l}\text { Marital } \\
\text { status }\end{array}$} & Single & 16.45 & 112.13 & 0.331 \\
\hline & Married & 14.33 & 105.33 & \\
\hline & Widowed & 30.00 & 136.92 & \\
\hline & Divorced & 0.00 & 58.50 & \\
\hline & Separated & 10.00 & 102.25 & \\
\hline \multirow[t]{5}{*}{ Education } & $\begin{array}{l}\text { Never attended } \\
\text { school }\end{array}$ & 15.56 & 108.22 & 0.412 \\
\hline & $\begin{array}{l}\text { Completed b/w } 1 \\
\text { and } 4 \text { years }\end{array}$ & 12.86 & 104.34 & \\
\hline & $\begin{array}{l}\text { Completed b/w } 5 \\
\text { and } 11 \text { years }\end{array}$ & 17.19 & 110.27 & \\
\hline & $\begin{array}{l}\text { Completed class } \\
12\end{array}$ & 20.00 & 119.56 & \\
\hline & $\begin{array}{l}\text { Completed } \\
\text { college/ } \\
\text { university }\end{array}$ & 11.14 & 98.74 & \\
\hline
\end{tabular}

knowledge of males (63.83\%). This difference may be attributed to the fact that females spend more time with mentally ill patients in families, especially in India.

The association between total knowledge about causative factors of mental illness with social distancing (proxy stigma) attitude practiced by community members towards mentally ill patients was found to be statistically associated ( $\mathrm{p}=0.001$ at $95 \% \mathrm{CI}$ and $\mathrm{r}=-0.381$ ). This indicates that there was a moderate reduction of stigma with increase in knowledge about causative factors of mental illness. This could be an evidence of general awareness and knowledge about mental health, in the community members.

The community members were moderately accepting of individuals with mental health problems, possibly because in, India people with mental illness commonly stay within the family and community. However, this virtual acceptance reveals the false beliefs and negative attitudes towards the mentally ill patients, highlighting the need for involving individuals suffering from mental illness in day-to-day work activities, socializing with them, helping them, spending time with them, and creating a positive environment for them.

The very common recognized causes and risks described in vignettes (depression and psychosis) were variety of socioeconomic issues (arguments, work difficulties, life decisions, addiction, death of close one, financial problems, unemployment and divorce or separation). Separation and alone or loneliness like factors, were perceived to be the cause of mental health problems according to the majority of respondents.

More than $60 \%$ of people were agreed to ask help from family members and for treatment ayurvedic doctor, psychiatrist and local doctors were preferable. This is possibly due to awareness and knowledge of mental health problems amongst the population of Udupi Taluk is high and education rate is also high.

When respondents were asked to open-ended questions about causation, more than half of participants had perceived unemployment, family problems, day to day arguments, addiction of family member, divorce, financial problems to be the cause of the problems described in depression vignette. A couple of the respondents also perceived that sexual harassment could also be the reason of the problem explained in the female vignette (depression).

These findings highlight a need to talk to close ones. It is also noted that divorced people were at increased risk of developing a mental health problem. A probable description for this somewhat, unclear finding is that while remaining unmarried or becoming divorced is absolutely socially handicapping in this perception, it is also largely recognized that some marriages are very stressful, for women in particular, if there is continuous conflict with the husband, family members or in-laws, or if the husband drinks or gambles, resultant in financial problems, work difficulties, day to day disputes in the family. The study found that the people who were unemployed and divorced or separated were more likely to suffer from mental health problems. Similar, studies also suggested that women are more prone to mental health problems. ${ }^{11}$ However, this was not observed in Udupi Taluk. While literature review recommends that faith of Indian population on spiritual healers for mental health problems is a bit more, however this study found the opposite. ${ }^{13}$ A very insignificant population believed that witch doctors and priests could help people with mental health problems. This finding challenges the common misconceptions about Indian society and its reliance on non-scientific and occult methods.

In relation to supposed risk groups, the respondents reported that there is not much difference in males and females suffering from the problems, whereas females are more prone to depression as compared to males. Although, literature review suggests that females are more vulnerable to some of the common mental health problems, men are more vulnerable to substance abuse and addiction, and a higher risk of schizophrenia or psychosis. Also, the age was seen to be moderately significant, as older individuals were more likely to develop a mental health problem when compared to others in the community. ${ }^{14}$

Most importantly, a small proportion of participants agreed that it is best to avoid the person, as he may be dangerous, hide the problem, not to socialize with the individual. The finding of this study suggested that there was very less social distancing found in community members towards the individuals suffering from common mental health problems. Whereas, the opposite was highly examined towards the person described in the psychosis vignette.

The findings from this study indicate that, almost all health care providers had attended training in mental health, but only for 1-3 days. Despite the limited access to trainings in mental health, the majority of respondents felt confident in recognizing mental health problems including signs and symptoms of depression, stress, anxiety and psychosis. The majority of participants assumed that mental health problems are very common in the community. The commonly held opinions by them were considering the decentralization of all medicines, more trainings, campaigns, IEC material essential to raise awareness at community levels. The report from survey by Gururaj et al. also suggested that there is need of governance strengthening, capacity building of institutions and professional, and framework for implementation of the program. ${ }^{15}$ This paper brings to light the ground realities when it comes to awareness and discrimination associated with mental illness. We strongly believe in and advocate increased training for healthcare workers, so that mental health can be identified and treated at the earliest. Common people need to be sensitised about impact of their individual actions on the mental health of people in their communities.

\subsection{Some perceptions noted during the study of healthcare providers}

Most than $60 \%$ of participants said that doctor/psychiatrist from district hospital, National Mental Health Program team visited PHC's, CHC's and three members from the team social worker, psychologist and nurse also visited to the house if patient needed counseling and is unable to visit health centre.

Regarding training program for healthcare providers the most common complaint of the stakeholders about the training was that they were of very short duration, held annually and were inadequate.

Community people perception about NMHP was that there is more 
need of publications through newspapers, advertisements, so that people came to know about general mental health problems, programs run by the government, whom to approach at right time, need more medicines at PHC's and sub centers, to appoint psychiatrists at all health centers so that it will become easy for local people to approach right person at right time which helps to reduce stigma, beliefs in local doctors.

When asked about the existing programs for prevention of mental illness and treatment, majority of respondents spoke about National Mental Health program, less than half of respondents also spoke about other programs that promote mental health, such as once in a week in a hospital ARSH program was conducted, which was for adolescent counseling and treatment for patients of age 9-19 years and National Mental Health Program.

Based on the study results, views of community respondents and interaction with healthcare providers of Udupi Taluk, the following recommendations were made:

- Provide more information about mental health problems and treatment through local media, advertisements, and recovery stories of patients in newspapers, campaigns in community.

- Awareness and health promotion campaigns at community level, on weekends or public holidays, so that males and females both can benefit.

- An assessment of common mental health disorders (stress, depression, etc.) to be done similar to non-communicable diseases.

- Health promotion must be done at community levels, and focus on strengthening of referral/care and provision of services in all healthcare centers.

- Existing facilities need to be upgraded and made more accessible to community members for reintegration, care and support of persons with mental illness. It will require an establishment of latest services, in addition to current services, which can reach the population through health care providers and government.

- Planned/logical approaches could enhance mental health care facilities as primary care services at the grass-root level.

- Trainings and knowledge dissemination for healthcare providers must align with the ground level realities and requirements.

Some limitations were there like the tool was entirely adopted from a community-based study previously in rural parts of Maharashtra. Thus, it doesn't completely match contextually with Udupi Taluk's demography and socioeconomic factors. People responding to the social distancing scale may give socially desirable responses, which might lead to bias findings from the scale. More than $60 \%$ of the community members and NMHP stakeholders spoke about private mental healthcare facilities in the Taluk. However, the stakeholders included in this study were only those of government sector. The perception of stakeholders can't be held as the standard because of the same. The private healthcare providers were not included because of the constraints of time and feasibility.

\section{Conclusion}

More than $60 \%$ of the community members have knowledge and awareness about causal factors of mental health problems in this region.
This may be due to the presence of many educational institutes and tertiary care hospital in this region, and also general awareness and high levels of literacy. The healthcare providers required more training, IEC material through life skills education at Educational Institution as well as community using standard training modules. Implementation District Mental Health Program activities with support of the DMHP team. Regular reports of DMHP should be provided by the PHC/CHC/DH to State Nodal officer of NMHP. Promote advocacy for Mental Health and maintain records of severely mentally ill patients. Provision of DMHP camps in general health camps, vaccination camps, etc. Training of health workers and community leaders and staff that supports to inspire them. Trainings need to focus on identifying common mental health problems, being aware of the resources available and centers where patients can be referred, being trained in basic counseling so that patient can be dissuaded from taking any drastic steps or causing self-harm. It is necessary to provide mental health care in the sub centers, PHC, CHC and to promote more awareness about general mental health problems, and treatment at community levels or grass root levels and patients from hard to reach areas. There is need to aware the community about the National Mental Health program, and services provided by the government for mental health problems, so that people can get best and economically affordable care and possibility to reach nearby health centers especially in rural areas.

\section{References}

1 Division of Non communicable Diseases. Mental Health Research in India (Technical Monograph on ICMR Mental Health Studies). New Delhi: Indian Council of Medical Research V. Ramalingaswami Bhawan Ansari Nagar; 2005, 2005. Available from: http://www.icmr.nic.in/publ/Mental\%20Helth\%20.pdf.

2 World Mental Health Day. India's Mental Health Crisis in Numbers. HuffingtonPostIndia; 2016. Availablefrom http://www.huffingtonpost.in/2015 /10/09/world-mental-health-day-indias-mental-health-crisis-in-numbers.

3 Mental health, World Health Organization. Available from: http://www.who.int /topics/mental_health/en; 2016.

4 Prince M, Patel V, Saxena S, et al. No health without mental health. Lancet. 2007;370 (9590):859-877.

5 Wang PS, Aguilar-Gaxiola S, Alonso J, et al. Use of mental health services for anxiety, mood, and substance disorders in 17 countries in the WHO world mental health surveys. Lancet. 2007;370(9590):841-850.

6 World Health Organization. Integrating Mental Health into Primary Care: A Global Perspective. Geneva: World Health Organization; 2008.

7 WHO Mental Health Gap Action Programme. Scaling up Care for Mental, Neurological and Substance Use Disorders. Geneva: World Health Organization; 2008. http://www. who.int/mental_health/mhgap_final_english.pdf (Google Scholar).

8 Patel V, Araya R, Chatterjee S, et al. Treatment and prevention of mental disorders in low-income and middle-income countries. Lancet. 2007;370(9591):991-1005.

9 Patel V, Sumathipala A, Khan MM. South Asia region. In: Bhui K, Bhugra D, eds. Culture and Mental Health - a Comprehensive Textbook. London: Hodder Arnold; 2007.

10 World Health Organization: Mental Health Atlas. Geneva: World Health Organization; 2006.

11 Kermode M, Bowen K, Arole S, Joag K, Jorm A. Community beliefs about causes and risks for mental disorders: a mental health literacy survey in a rural area of Maharashtra, India. Int J Soc Psychiatr. 2009;56(6):606-622.

12 Venkatesh B, Andrews T, Mayya S, Singh M, Parsekar S. Perception of stigma toward mental illness in South India. J Fam Med Prim Care. 2015;4(3):449.

13 Khandelwal SK, Jhingan HP, Ramesh S, Gupta RK, Srivastava VK. India mental health country profile. Int Rev Psychiatr. 2004;16:126-141.

14 McGrath J, Saha S, Chant D, Welham, Schizophrenia J. A concise overview of incidence prevalence and mortality. Epidemiol Rev. 2008;30:67-76.

15 Gururaj G, Varghese M, Benegal V, et al. National Mental Health Survey of India, 201516: Mental Health Systems. Bengaluru: National Institute of Mental Health and Neuro Sciences, NIMHANS Publication; 2016. No. 130. 